\title{
SyNOPTIC MEASUREMENT OF DYNAMIC OCEANIC FEATURES
}

\author{
By Brian K. Haus, Hans C. Graber
}

and Lynn K. Shay

$\mathrm{S}$ High-frequency (HF) mode are becoming a widely high-frequency (HF) mode are becoming a widely used and accepted tool for measuring surface currents for coastal oceanographic research. Their history, theory of operation, and accuracy relative to other sensors are discussed elsewhere in this issue. We will focus on the advantages of the HF radar sampling strategy.

The Ocean Surface Current Radar (OSCR) HF (25.4 MHz) radar provides a time series of surface currents at each of its 700 measurement cells. Current velocities have been reported to agree with moorings and shipboard current observations to within 10-15\% over a wide range of conditions by Matthews et al. (1987), Shay et al. (1995), Chapman et al. (1997) and Graber et al. (1997). This order of agreement between sensors is obtained even though there are considerable differences in measurement depth and spatial and temporal sampling resolution. The advantage of HF radars is their capability to sample a large region synoptically at a resolution on the order of $1 \mathrm{~km}$, which provides maps of dynamic flow features that can greatly enhance understanding of important oceanic processes.

Four different OSCR experiments conducted between 1993 and 1996 will be discussed in the context of the different types of oceanic processes that can be effectively sampled. In each of these experiments the OSCR system was used in conjunction with in situ observations, which greatly enhance the utility of the measurements.

\section{Gulf Stream Frontal Features and Mesoscale Eddies}

Strong reversals in current meter records were first associated with cyclonic eddies that form along the inshore edge of the Florida Current by Lee (1975). A synoptic picture of these spin-off eddies was obtained using OSCR in a joint study

Brian K. Haus, Hans C. Graber, and Lynn K. Shay, Rosenstiel School of Marine and Atmospheric Science, University of Miami, 4600 Rickenbacker Causeway, Miami, FL 331491049, USA. on pollution transport and fish larvae recruitment off the Florida Keys during May 1994 (Fig. 1). Numerous small scale eddies entered the OSCR domain from the west and exited to the east. These eddies traversed the domain on a timescale of every $2-5 \mathrm{~d}$. The surface expression of these features was easily detected in the OSCR current maps. Vortex-like circulation features were identified with a diameter of $10-30 \mathrm{~km}$ and swirl speeds of $10-50 \mathrm{~cm} \mathrm{~s}^{-1}$ (Graber et al. 1995). The path of the spin-off eddies was generally along the $150-\mathrm{m}$ isobath, which is marked by the presence of the

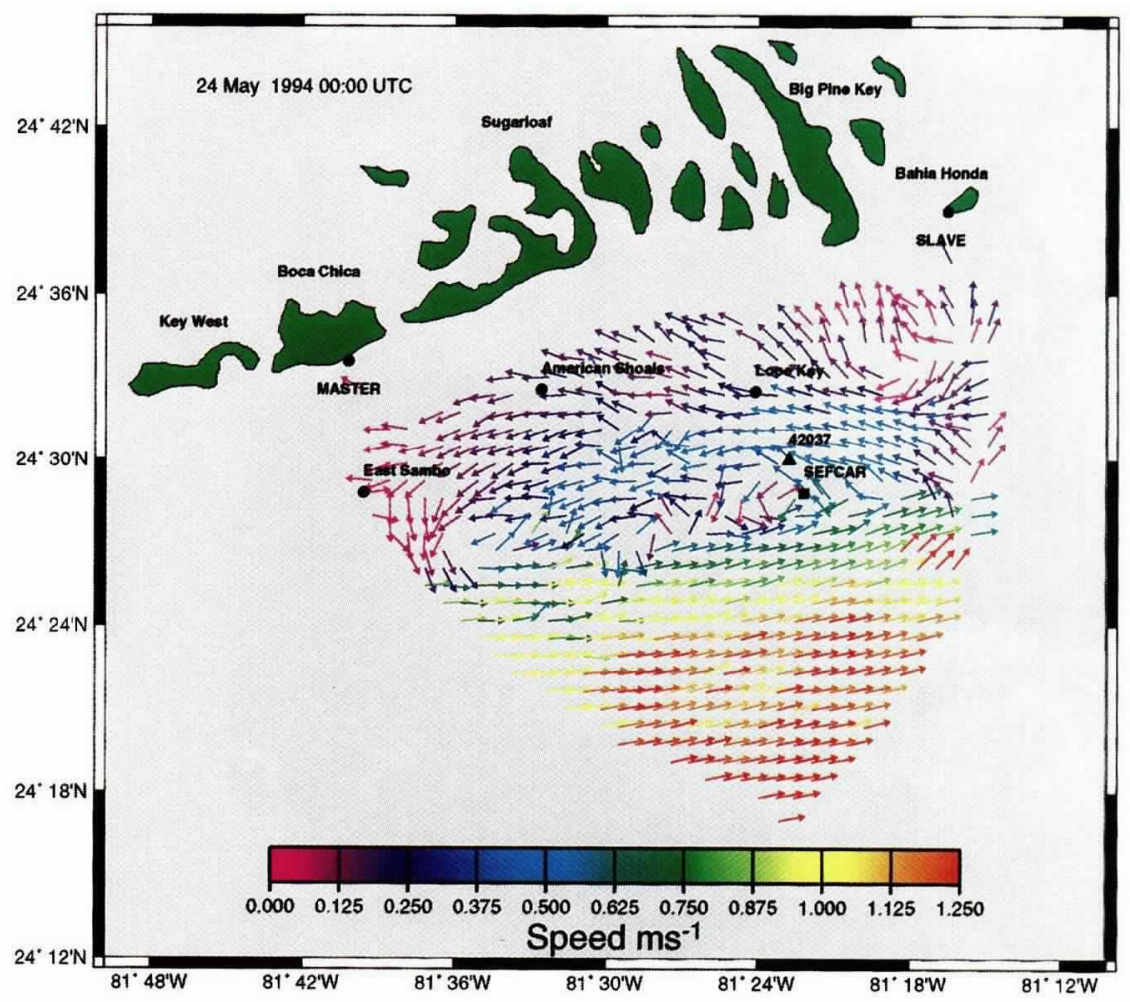

Fig. 1: Surface currents measured using OSCR off the Florida Keys on 24 May 1994 at 0000 GMT. "Master" and "Slave" denote the locations of the two radar stations required to measure vector currents. Looe Key, American Shoals, and East Sambo are shallow coral reefs where bottom-mounted current meters were located. The bathymetry drops off sharply outside these reefs. 


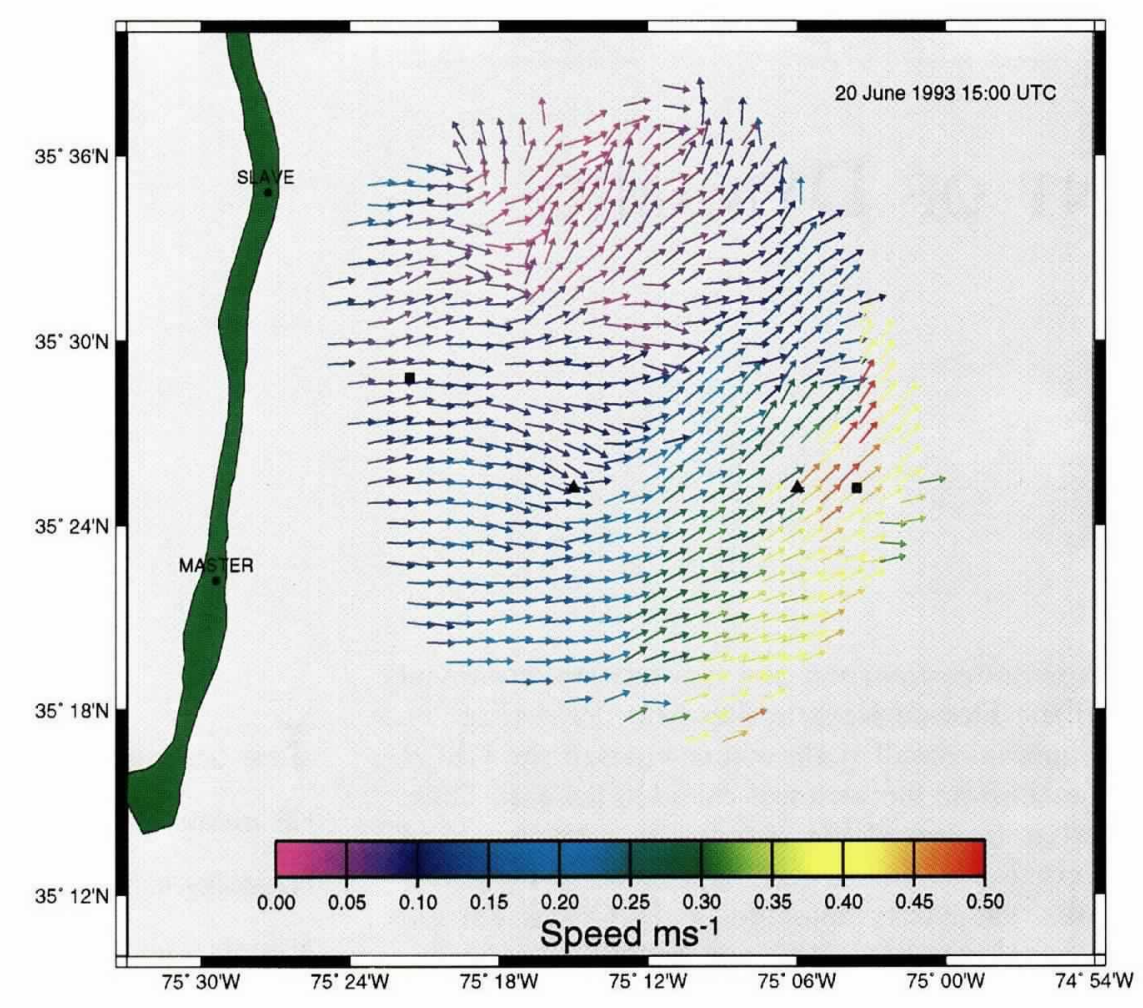

Fig. 2: Surface currents measured using OSCR during the HighRes-II experiment on 1500 UTC 20 June 1993. $\boldsymbol{\boldsymbol { Q }}$, positions of current meter moorings; $\boldsymbol{\Lambda}$, National Data Buoy Center wave buoys. Note the strong frontal feature in the center of the domain that resulted from the collision of two water masses.

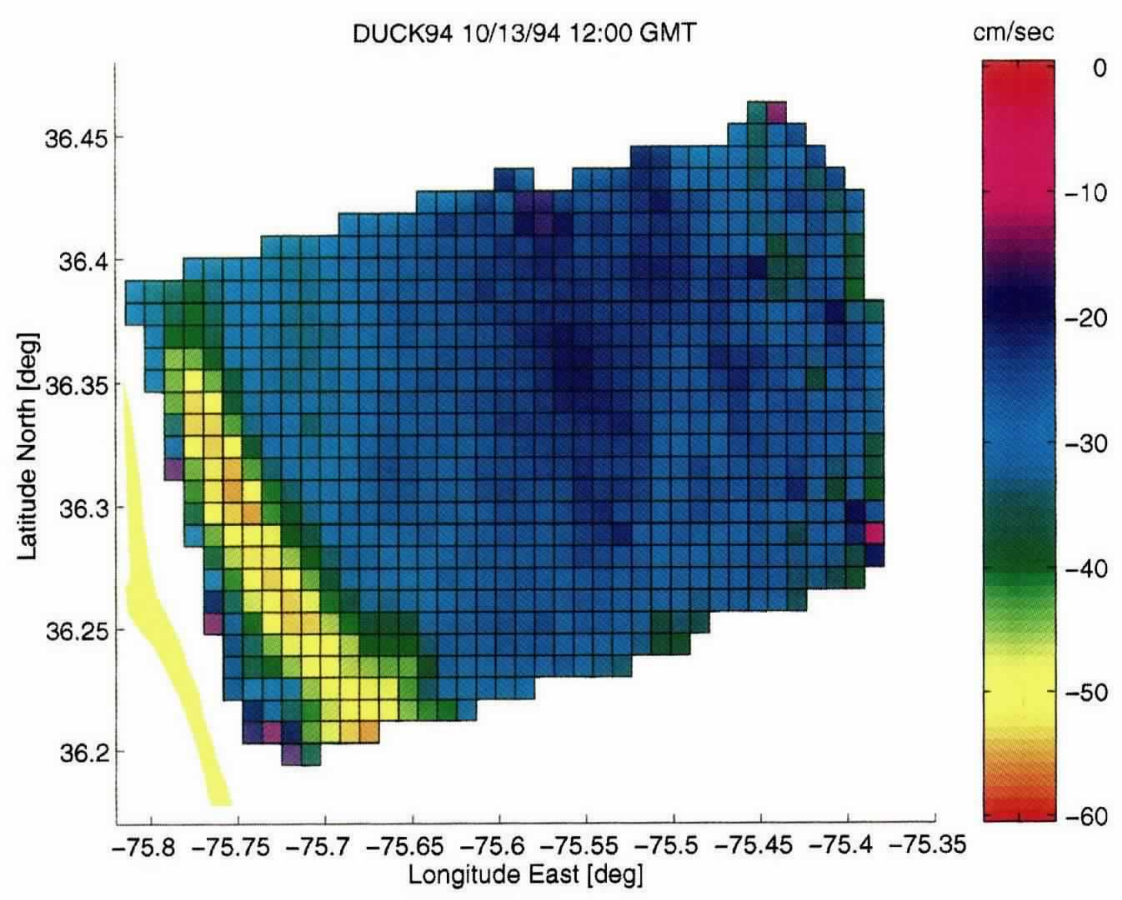

Fig. 3: Detided along-shelf velocities measured by OSCR during the DUCK94 experiment in October 1994. Negative velocities denote flow toward the southeast in the direction of Kelvin wave propagation.
SouthEast Florida And Caribbean Recruitment program (SEFCAR) buoy in Figure 1, and their propagation speed was $\sim 1 \mathrm{~km} / \mathrm{h}$.

Limouzy-Paris et al. (1997) used these measurements to study the translocation of coral reef fish larvae. The OSCR surface current maps provided the time, length, and velocity scales of the small scale eddies. Combining these maps with biological measurements of abundance was useful for assessing the recruitment and translocation patterns of coral reef fish larvae in ways that were not possible by conventional measurement techniques (see Graber and Limouzy-Paris, 1997, this issue).

During the high resolution remote sensing experiment (HighRes-II) experiment off the Outer Banks of North Carolina, the OSCR system was operated for $1 \mathrm{mo}$. The measurement region was strongly impacted by the position of the "North Wall" of the Gulf Stream. In Figure 2 the surface currents when the Gulf Stream meandered closer to shore are shown. The OSCR can clearly show the shear in this region as well as frontal features. Convergence and divergence of surface currents can be identified, precisely located, and quantified using the OSCR data. This is very useful for interpreting interferometric synthetic aperture radar (INSAR) images, because they are strongly influenced by surface currents that may concentrate or diffuse wave energy (Graber et al. 1996). The increased concentration of surfactant material in a convergence zone can also have a strong influence on short ocean surface waves.

Although other remote sensing techniques such as advanced very high resolution radiometer (AVHRR) could also show the position of the Gulf Stream North Wall, the presence of flow features is not always marked by temperature changes. This is the case with the buoyant coastal current emanating from the Chesapeake Bay (discussed in the next section), which did not have a significant temperature difference from the ambient shelf water during October 1994. Multispectral sensors would be required to identify this type of frontal boundary.

\section{Coastal Buoyancy Current}

A series of OSCR observations were obtained during the DUCK94 experiment at the U.S. Army Corps of Engineers Field Research Facility at Duck, NC, in October 1994 (Haus et al., 1995). Three periods of downwelling favorable winds $\left(>10 \mathrm{~m} \mathrm{~s}^{-1}\right)$ were observed during the month of measurements.

During downwelling favorable winds, buoyant water that is propagating at increased speeds relative to the ambient shelf water is forced against the coast and becomes organized into a coastal current (Fig. 3). The coastal current reacts rapidly to shifts in the wind direction. The offshore edge of the buoyant flow moved $5 \mathrm{~km}$ closer to shore over a period of $6 \mathrm{~h}$ on 10 October 1994 when the 
wind turned more onshore. This corresponds to a frontal propagation speed relative to the ground of $23 \mathrm{~cm} \mathrm{~s}^{-1}$. The coastal current has a large degree of variability in the along-shelf direction; bulges and gaps are observed even during periods of consistent downwelling winds. When the buoyant jet was forced close to the coast during the three strong downwelling events, salinity measurements at moorings show that the buoyant flow may contact the bottom (Haus et al., 1996).

It is clear from the surface current maps that under varying wind regimes, buoyancy and wind forcing interact to drive nearshore circulation patterns. Hickey and Hamilton (1980) used a spin-up model of the Washington-Oregon shelf to determine that the buoyancy flow could become detached from the shelf during upwelling winds. Khourafalou et al. (1996) used a 3-D Blumberg-Mellor model for the circulation of the south Atlantic bight to simulate the effects of wind and discharge rates on a coastal buoyancy current. They found that it is possible to have a southward flowing buoyancy current in nearshore waters opposing the predominant wind direction, particularly during periods of strong runoff and light upwelling winds. The OSCR surface current maps collected during DUCK94 show the advection of low salinity water up to $35-\mathrm{km}$ offshore during upwelling winds. Nearshore water was also observed moving southward against the wind direction consistent with the model of Khourafalou et al. (1996).

Münchow and Garvine (1993) showed that the Delaware Bay coastal current contacts the bottom in the absence of upwelling favorable winds. They contrasted this with previous work on the Chesapeake Bay outflow that had showed a thin layer of buoyant flow. The ratio of the horizontal shear to the Coriolis parameter was of order one in the source region near the estuary mouth. Further downstream in the coastal current region, they found that this ratio was much smaller. Our results for the spatial distribution of this ratio show a much more complex picture of the coastal current shear. Under both wind regimes there are regions of high lateral shear where the ratio is $\mathrm{O}(1)$. The water mass boundaries are much sharper and lead to higher shear than Münchow and Garvine (1993) suggest. The high resolution of the OSCR fields and the ability to accurately define the vorticity from gridded surface current fields allows the observation of these localized regions of high lateral shear.

The value of synoptic surface current measurements when used in combination with moorings or shipboard profilers is obvious in the spatial variation of the position and speed of the buoyant coastal current. There is no way to select a single location or even a transect that would adequately describe the behavior of the coastal current in this region, even though the coastline is relatively straight and there are no large bathymetric features. A shipboard survey can cover the region, but it would take a least a day to traverse the nearshore (within $20 \mathrm{~km}$ of the coast) enough times to define

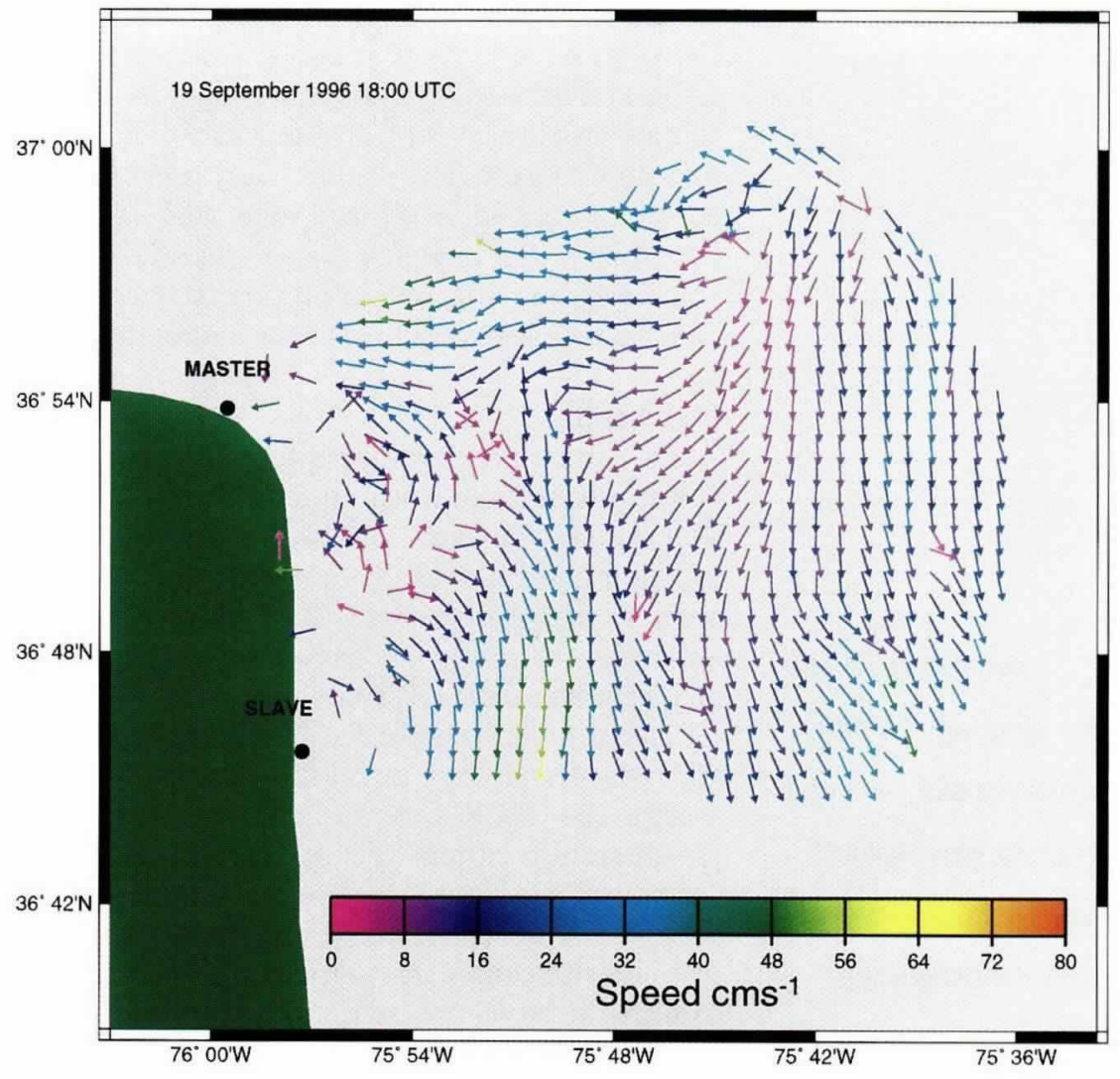

Fig. 4: Surface currents measured by OSCR during the COPE experiment on 1800 UTC 19 September 1996. The currents shown were measured during a tidal inflow into Chesapeake Bay.

the jet shape as it moves along the coast. With a large degree of changes occurring to the jet position and shape in only $6 \mathrm{~h}$, an inaccurate picture of the coastal current behavior would result. During accelerating or decelerating flow a ship survey running two transects at the northern and southern reaches of the OSCR domain would reach different conclusions on the change in the width of the coastal current depending on the order in which the transects were conducted. Matthews (1997) simulated processes such as mesoscale eddies and frontal meanders and showed that a shipboard survey using towed instruments led to a $40-50 \%$ increase in the root mean square (rms) error because of temporal changes in the features.

\section{Estuarine-Shelf Interactions}

The Chesapeake outfall plume experiment (COPE) was conducted using the OSCR HF radar just south of the Chesapeake Bay mouth in October 1996. The surface currents without tidal constituents removed are shown in Figure 4 for a tidal flow moving into Chesapeake Bay. There is a very complex flow pattern during the incoming tide that is strongly influenced by the local bathymetry and wind direction. The overall flow is toward the south, with westerly inflow occurring offshore of the mouth. There are indications that there is flow
Our results for the

spatial distribution of this ratio show a much more complex picture of the coastal current shear. 
... combining remote

sensing with in situ

observations . . . can

lead to new insights

in coastal and biolog-

ical oceanography. exiting the mouth very close to the master site at Cape Henry, VA. There is also a divergence region between flow moving into the bay and the ambient southward flow at $36^{\circ} 51^{\prime} \mathrm{N}$ and $75^{\circ} 54^{\prime} \mathrm{W}$. Faster moving nearshore flow is most likely because of the buoyancy forcing on fresher water that has exited the estuary. The complexity of these flow patterns emphasizes the difficulty in making in situ observations that are representative of the entire flow field.

\section{Conclusion}

HF radars are a valuable tools for measuring ocean processes in a variety of dynamic regimes. The synoptic coverage and well-defined sampling location and interval of the radar measurements are very useful for quantifying tidal flow patterns, submesoscale eddies, coastal buoyancy currents, and estuarine-shelf exchange processes. This is by no means an exhaustive list of the applications of HF radar technology to coastal oceanographic research. The OSCR system can provide valuable regional surface current vectors and wave height information. However, combining remote sensing with in situ observations of important parameters of interest, such as the vertical current structure, salinity, or larval concentrations, can lead to new insights in coastal and biological oceanography.

\section{Acknowledgments}

The authors thank Jorge Martinez, Louis Chemi, John Hargrove, and Nick Peters, whose dedicated field work with OSCR in all of these experiments was invaluable, and Slavica Nikolic who produced the graphics. The results discussed here were funded by the Office of Naval Research through grants N00014-91-J-4133 and N00014-91-J-1775 (HighRes), N00014-94-1-1016 (DUCK94), and N00014-96-1-1065 (COPE-I) and by the U.S. Coast Guard through SFOSRC/OPRC.

References

Chapman, R.D., L.K. Shay, H.C. Graber, J.B. Edson, A. Karachintsev, C.L. Trump and D.B. Ross, 1997: On the accuracy of $\mathrm{HF}$ radar surface current measurements: in- tercomparisons with ship-based sensors. J. Geophys. Res., 102, 18,737-18,748.

Graber. H.C., B.K. Haus, L.K. Shay and R.D. Chapman, 1997: HF radar comparisons with moored estimates of current speed and direction: Expected differences and implications. J. Geophvs. Res., 102, 18,749-18,766.

, T.N. Lee, B.K. Haus, C.G.H. Rooth, E.J. Williams and L.K. Shay, 1995: Observations of ocean surface currents off the south Florida Keys using an HF Doppler radar. South Florida Oil Spill Research Center Report, University of Miami. Miami, FL. 177 pp.

and C.B. Limouzy-Paris, 1997: Transport patterns of tropical reef fish larvae by spin-off eddies in the Straits of Florida. Oceanography, 10, 68-71.

D.R. Thompson and R.E. Carande 1996: Ocean surface features and currents measured with SAR interferometry and HF radar. J. Geophys. Res., 101, 2581325832.

Haus. B.K.. H.C. Graber and L.K. Shay, 1996: Observations of a coastal buoyant jet with HF Doppler radar. Proc OCEANS 96 MTS/IEEE, Marine Technology Society, Ft. Lauderdale, FL, 1032-1037.

_- H.C. Graber, L.K. Shay and J. Martinez, 1995: Ocean surface current observations with HF Doppler radar during DUCK94 experiment. Technical Report RSMAS 95-010, University of Miami, Miami, FL. 104 pp.

Hickey, B.M. and P. Hamilton, 1980: A spin-up model as a diagnostic tool for interpretation of current and density measurements on the continental shelf of the Pacific northwest. J. Phys. Oceanogr., 10, 12-24.

Khourafalou, V.H., T.N. Lee, L.-Y. Oey and J.D. Wang, 1996 The fate of river discharge on the continental shelf. 1 . Modeling the river plume and the inner shelf coastal current. J. Geophys. Res. 101, 3415-3434.

Lee, T.N., 1975: Florida Current spin-off eddies. Deep-Sea Res., 22, 753-765.

Limouzy-Paris, C.B.. H.C. Graber, D.L. Jones, A. Röpke and W.J. Richards, 1997: Translocation of larval coral reef fishes via sub-mesoscale spin-off eddies from the Florida Current. Bull. Mar. Sci., 60, 966-983.

Matthews, J.P.. J.H. Simpson and J. Brown, 1987: Remote sensing of the shelf sea currents using an HF radar system. I. Geophys. Res., 93, 2302-2310.

Matthews, P.A.. 1997: The impact of nonsynoptic sampling on mesoscale oceanographic surveys with towed instruments. J. Atmos. Ocean. Tech., 14, 162-174.

Münchow, A. and R.W. Garvine, 1993: Dynamical properties of a buoyancy-driven coastal current. J. Geophys. Res. $98,293-322$.

Shay, L.K., H.C. Graber, D.B. Ross and R.D. Chapman, 1995: Mesoscale ocean surface current structure detected by high-frequency radar. J. Atmos. Ocean. Tech., 12, 881$900 . \square$ 